\title{
Reactivation of Fetal Erythropoiesis during the Postnatal Period
}

\author{
MANFRED GAHR ${ }^{(18)}$ AND GÜNTHER HERLEMANN \\ Universitäts-Kinderklinik, Göttingen, West Germany
}

\section{Summary}

Using isopycnic gradient centrifugation, blood samples from adults, from umblilical cord, from newborn infants and from infants of different age group up to the age of $8 \mathrm{mo}$, were separated into seven fractions according to cellular age. We measured the number of erythrocytes and reticulocytes, mean cellular volume, mean cellular hemoglobin concentration, and the concentration of hemoglobin in each of the seven fractions. The distribution of erythrocytes within the gradient during postnatal aging revealed a bimodal distribution between 2-4 mo. Correspondingly, during the age of $2-8$ mo the oldest cells did not contain the highest hemoglobin $\mathrm{F}$ concentration as was observed in the younger age group. From these data we conclude that the postnatal disappearance of hemoglobin $F$ is not a continuous process.

\section{Abbreviations}

HbF, hemoglobinF

MCHC, mean cellular hemoglobin concentration

$\mathrm{MCV}$, mean cellular volume

During the first months of life, properties distinguishing neonatal from adult erythrocytes are lost and are replaced by the corresponding adult properties (9). To define this process more exactly we separated blood, which is comprised of cells with different lifespans into subpopulations of different cell age at various moments during the first months of life. The aim of this study was to determine the decrease of $\mathrm{MCHC}, \mathrm{MCV}$ and $\mathrm{HbF}$ using ficoll-gradient centrifugation which allows the discrimination between cells of different ages.

\section{MATERIALS AND METHODS}

Materials. Ficoll 400 was purchased from Pharmacia (12) and sodium metrizoate (Triosil) was the product of Nyegaard (13). All other chemicals were from Merck (14).

Methods. Erythrocytes were separated into seven fractions according to age by isopycnic gradient centrifugation using the method of Turner et al. (10). Details of the procedure are published elsewhere (8). There it is shown that also fetal blood can be separated in young and old erythrocytes by the method of Turner et al.

Hemoglobin concentration was determined by the cyanmet hemoglobin method. MCV and MCHC values were measured or calculated with a Coulter Counter, model FN. Reticulocyte counts were done after staining with $1 \%$ brillantcresylblue. $\mathrm{Hb}$ F concentration was measured using the method of Betke et al. (4). Adult blood was obtained from healthy male laboratory personal (group F, $n=14$ ). Cord blood was drawn from the placenta, directly after birth, of uncomplicated term pregnancies (group A, $n=10$ ). We used erythrocytes that were the byproduct of diagnostic blood sampling from term infants up to age of 8 mo. The infants were hospitalized because of nonhematologic disorders. Four groups were formed according to the age of the infants: up to 1 mo (group $\mathrm{B}, n=16$ ), $1-2$ mo (group C, $n=7$ ), 2-4 mo (group D, $n=9$ ), and 5-8 mo (group $\mathrm{E}, n=12$ ).

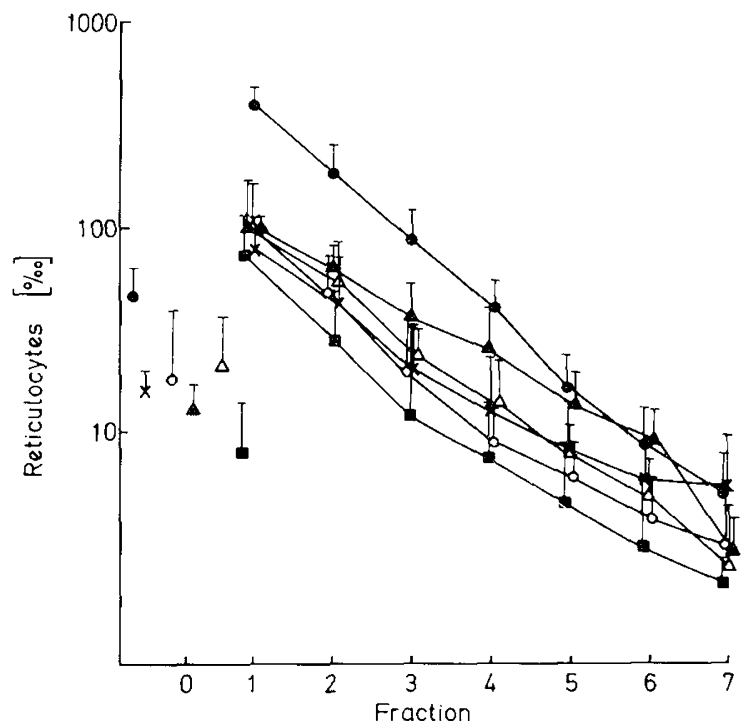

Fig. 1. Blood from the umbilical cord (- from infants of different age groups (group $\mathrm{B}=$ up to 1 mo, $\mathrm{O} \longrightarrow \mathrm{O}$; group $\mathrm{C}=1-2$ mo., $\mathbf{A} \mathbf{A}$; group $\mathrm{D}=2-4 \mathrm{mo}, \triangle \longrightarrow \triangle$; and group $\mathrm{E}=5-8 \mathrm{mo}$ $\square$ ) and from adults $(\times-\times)$ was separated in layers of different specific density, e.g., different cell age (fraction $1-7$ ). The values for whole blood (not separated) are shown under fraction 0 . In each layer the percentage of reticulocytes was determined for the different age groups.

\section{RESULTS}

As shown in Figure 1, the percentage of reticulocytes decreases with increasing specific density,i.e., with increasing cellular age. The decline is most pronounced in group A (cord blood), where the "youngest" cells contained $40 \%$ reticulocytes.

The distribution of erythrocytes among the different layers of the gradient was calculated by measuring the hemoglobin content of each layer. We considered this a measure of the number of erythrocytes because the mean hemoglobin content of individual erythrocytes was similar among the different layers. This value was expressed as the percentage of the total hemoglobin recovered from the gradient (Table 1). Erythrocytes from group $\mathrm{F}$ were distributed "normally," i.e., the maximum number of cells as confined to the fourth layer of the gradient. Compared with this result, the maximum number of erythrocytes of group $\mathrm{A}-\mathrm{E}$ 
Table 1. Number of erythrocytes within the different layers of the gradient in all age groups (expressed as the percentage of the total hemoglobin layered on top of the gradient). The mean values $\pm S D$ are given. The layer with the maximum number of erythrocytes in each age group is underlined.

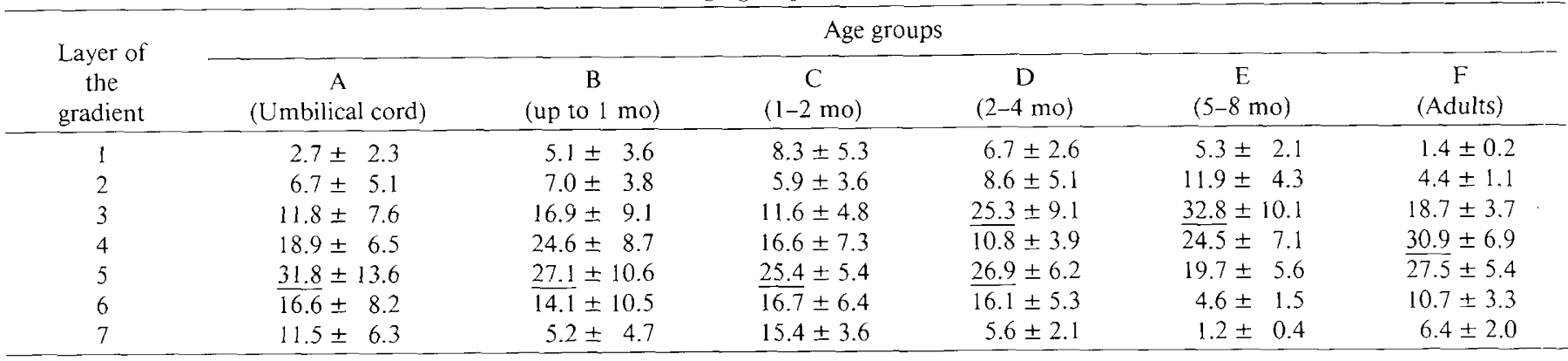

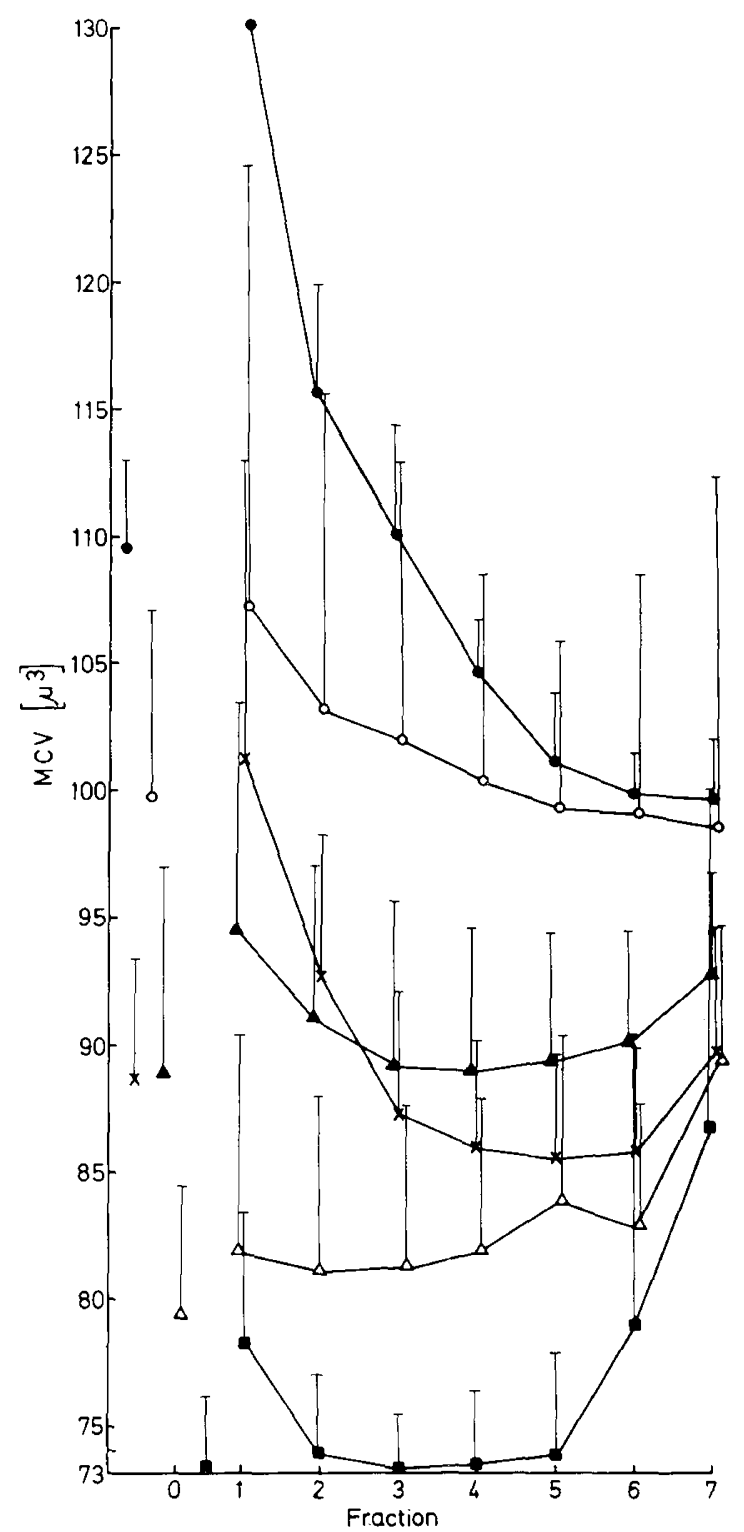

Fig. 2. Mean cellular volume (MCV) in the different layers. For explanation see legend to Figure 1.

were concentrated in layers with either a higher or lower specific density, e.g., layer 5 of group B had a higher specific density and layer 3 of group $E$ had a lower specific density.

The MCV decreased with increasing specific density in cord blood (group A) and in erythrocytes from group B. This changed continuously from group $\mathrm{C}$ to group $\mathrm{E}$, where the fraction with the highest MCF was that with the oldest cells (Fig. 2). MCHC

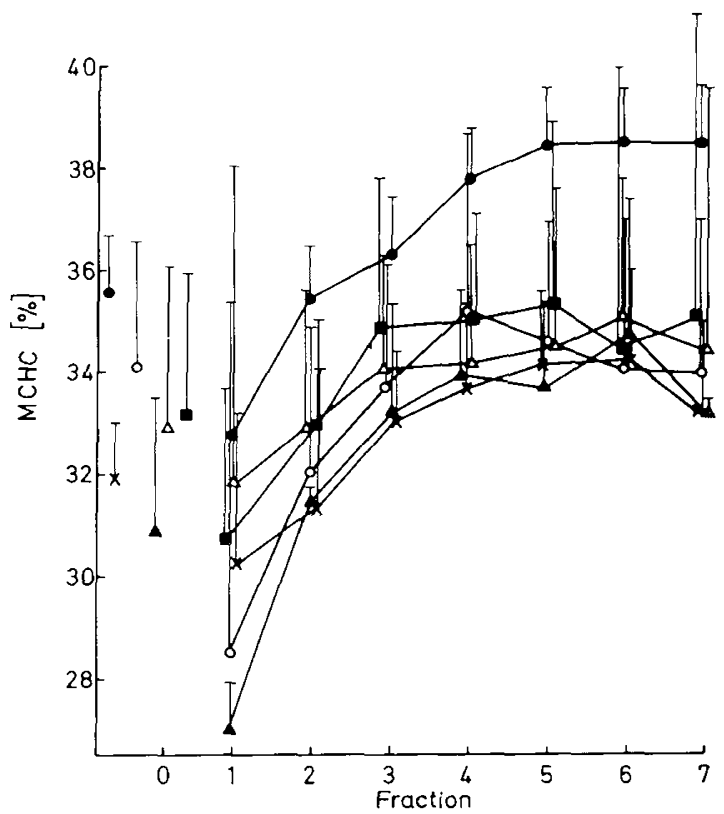

Fig. 3. Mean cellular hemoglobin concentration (MCHC) in the different layers. For explanation see legend to Figure 1.

increased with increasing specific density in all groups, and was most pronounced in group A (Fig. 3). The percentage of $\mathrm{Hb} \mathrm{F}$ was determined in the hemoglobin recovered from the different layers of the gradient. The $\mathrm{Hb} \mathrm{F}$ concentration increased continuously with increasing specific density of the cells in cord blood (group A) and in group B and C. Erythrocytes from group D and $\mathrm{E}$ showed a maximum of $\mathrm{Hb} F$ concentration not in the layer with the highest specific density but in those with lower density (Fig. 4).

\section{DISCUSSION}

We suggest that the process of replacement of fetal erythrocytes (large, with high hemoglobin content) by adult ones (small, with low hemoglobin contents) is not a continuous process. The distribution of erythrocytes during postnatal aging revealed two peaks at the age of 2-4 mo (group D, Table 1). So two populations of erythrocytes, differentiated at least by their specific density were present during this age. A similar finding was reported for young rats (11).

The change in MCV values during the process of postnatal aging of the infants and during cell aging within the different age groups can be explained as follows. Normally MCV declines with increasing age of the cells. This is true for erythrocytes from newborn infants (group A and B) and adults. At the age of 2-8 mo (group D and E), however, older cells have a higher MCV than younger ones. To explain this, one has to consider that MCV gradually decreases with postnatal age (the large fetal 


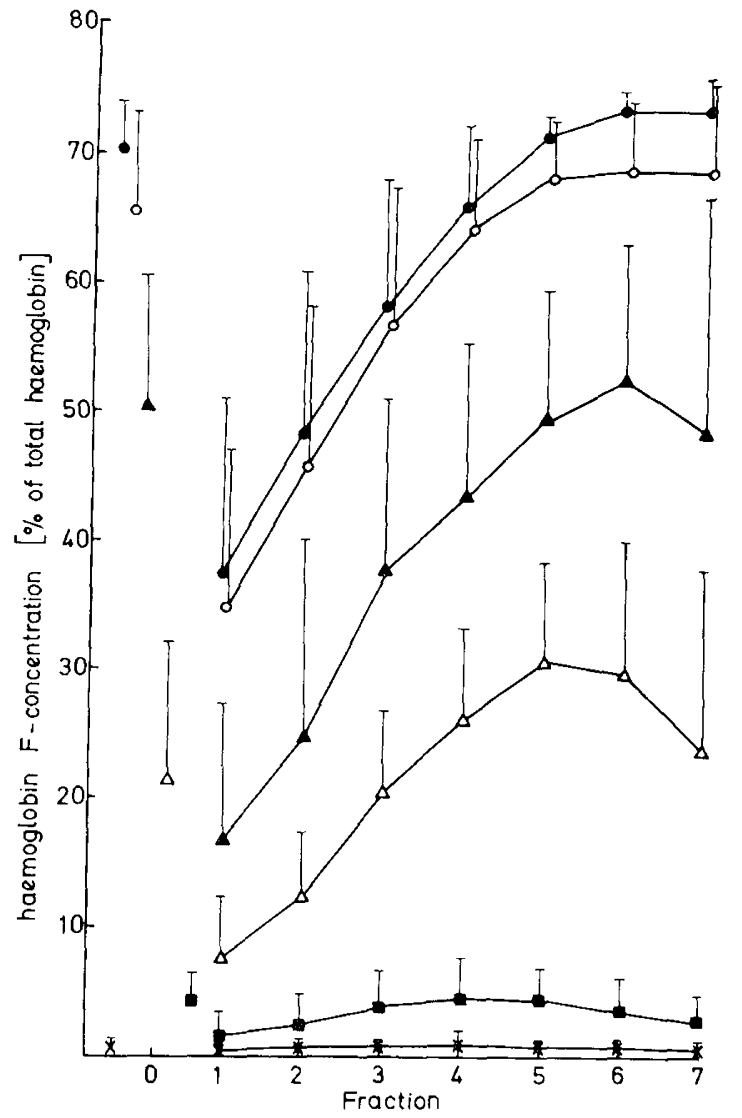

Fig. 4. Hemoglobin $F$ concentration in the different layers. For explanation see legend to Figure 1.

erythrocytes are replaced by small adult ones) so that there are two mechanisms acting against one another. The result is, that between the age of 2-8 mo the older fractions contain cells with high MCV, which have been formed at birth or during the first weeks thereafter. Despite an age-related water loss these high MCV-containing cells have a higher volume than the young ones, which have been formed later in the postnatal period.

By determining the $\mathrm{Hb} F$ concentration of whole blood and by measuring the $\mathrm{Hb} F$ synthesis in reticulocytes of the peripheral blood it has been shown, that the formation of $\mathrm{Hb} \mathrm{F}$ declines continuously during the postnatal age $(3,6)$. In contrast, our results suggest that the process of switching from fetal hemoglobin to adult hemoglobin formation is not continuous but interrupted by a temporary reactivation of $\mathrm{Hb} \mathrm{F}$ synthesis at about the age of $2 \mathrm{mo}$. In age group D and E (2-8 mo of age), the oldest cells did not contain the highest percentage of $\mathrm{Hb} \mathrm{F}$. Our interpretation is as follows: in old cells $\mathrm{Hb} F$ concentration is low, because the $\mathrm{Hb} \mathrm{F}$ synthesis was already low when these cells were formed. In middle aged celis $\mathrm{Hb} \mathrm{F}$ concentration is higher due to a temporary increase in $\mathrm{Hb} \mathrm{F}$ formation. In young cells $\mathrm{Hb} \mathrm{F}$ concentration is again low because the rate of $\mathrm{Hb} \mathrm{F}$ formation has been decreased again.

We speculate that this reactivation process could take place at the age of about 2 mo when a short reactivation occurs after the postnatal depression of erythropoiesis. A similar phenomenon is known to occur in adults during periods of rapid regeneration of the bone marrow [e.g., after bone marrow transplantation (2), after transient erythroblastopenia of childhood (1), during the recovery phase of severe iron deficiency anemia (7), and after infection (5)] when there is a transient increase in the number of $\mathrm{Hb} \mathrm{F}$ cells and in the rate of synthesis of $\mathrm{Hb} \mathrm{F}$ in peripheral blood reticulocytes.

The reason that other authors did not observe this reactivation during the postnatal period may be due to the fact that the small number of reticulocytes in the peripheral blood does not represent the true rate of $\mathrm{Hb} \mathrm{F}$ formation of the reticulocytes and erythroblasts in the bone marrow. Also by determining $\mathrm{Hb} \mathrm{F}$ concentration in whole blood a temporary reactivation of $\mathrm{Hb} \mathrm{F}$ synthesis may be overlooked because this method is too insensitive.

In summary, we think that the idea of a continuous decline of fetal to adult erythropoiesis is not true, at least, for $\mathrm{Hb} \mathrm{F}$ formation. Also the analysis of the specific density of the erythrocytes revealed a discontinuity. It appears that the switch from fetal to adult erythropoiesis is a very complex process, which awaits further analysis.

\section{REFERENCES AND NOTES}

1. Alter, B. P.: Fetal erythropoiesis in bone marrow failure syndromes. In: G. Stamatoyannopoulos and A. W. Nienhuis: Cellular and Molecular Regulation of Hemoglobin Switching. pp. 87-105 (Grune \& Stratton, New York. 1979).

2. Alter, B. P., Rappeport, J. M., Huisman,T. H. J., Schroeder, W. A., and Nathan, D. G.: Fetal erythropoiesis following bone marrow transplantation. Blood, 48: 843 (1976).

3. Bard, H.: The postnatal decline of hemoglobin F synthesis in normal full-term infants. J. Clin. Invest. 55:395 (1975)

4. Betke, K., Marti, H. R., and Schlicht. I.: Estimation of small percentage of foetal haemoglobin. Nature, 184: 1877 (1959).

5. Boyer, S. H. and Dover, G. J.: The in vivo biology of F cells in man. In: G. Stamatoyannopoulos and A. W. Nienhuis: Cellular and Molecular Regulations of Hemoglobin Switching. pp. 47-71 (Grune \& Stratton, New York. 1979).

6. Colombo, B., Kim, B., Atencio, R. P., Molina, C., and Terrenato, L.: The pattern of foetal haemoglobin disappearance after birth. Brit. J. Haemat., 32: $79(1976)$.

7. Dover, G. J.,Boyer, S. H., and Zinkham, W. H.: Production of erythrocytes that contain fetal hemoglobin in anemia. J. Clin. Invest, 63: 173 (1979).

8. Gahr, M., Meves, H., and Schröter, W.: Foetal properties in red blood cells of newborn infants. Pediatr. Res.. 13: 1231 (1979).

9. Oski, F. A. and Komazawa, M.: Metabolism of the erythrocytes of the newborn infant. Semin. Hematol., 12: 209 (1975).

10. Turner, B. M. Fisher, R. A., and Harris, $H$ : An association between the kinetic and electrophoretic properties of human purine-nucleoside-phosphorylase isoenzymes. Eur. J. Biochem., 24: 288 (1971).

11. Valet, G., Hofmann, H., and Ruhenstroth-Bauer, G.: The computer analysis of volume distribution curves. J. Histochem. Cytochem., 24: 231 (1976).

12. Pharmacia, Uppsala, Sweden.

13. Nyegaard, Oslo. Norway.

14. Merck, Darmstadt, West-Germany.

15. Informed consent was obtained from the parents of all infants included in this study.

16. The technical assistance of Mrs. F. Rüger is gratefully acknowledged.

17. This investigation was supported by the Deutsche Forschungsgemeinschaft (Ga 148/5).

18. Requests for reprints should be addressed to: M. Gahr, M.D., UniversitätsKinderklinik Göttingen, Humboldtallee 38, D-3400 Göttingen (West-Germany).

19. Received for publication September 16, 1982.

20. Accepted for publication April 25, 1983. 